\title{
Nonmotor Symptoms in Drug-Induced Parkinsonism and Drug-Naïve Parkinson Disease
}

\author{
Ji Sun Kim, Jinyoung Youn, Hyeeun Shin, Jin Whan Cho
}

\begin{abstract}
Background: The clinical manifestations of drug-induced parkinsonism (DIP) and Parkinson disease (PD) are nearly indistinguishable, making it difficult to differentiate DIP from PD, especially in the early stages. We compared non-motor symptoms between patients with DIP and those with drug-naïve PD in the early stages using the Non Motor Symptoms Scale (NMSS). Methods: We prospectively enrolled 28 patients with DIP, 35 patients with drug-naïve PD, and 32 controls with no history of neurological diseases or related medical problems. We investigated demographic characteristics, medical and drug history, parkinsonian motor symptoms, and non-motor symptoms. We used the NMSS to evaluate non-motor symptoms in all patients. Results: The total NMSS scores were higher in patients with PD than those with DIP, as were the scores for certain domains, including the cardiovascular, sleep/fatigue, urinary, sexual, and miscellaneous domains. When controlling for age and gender, the correlation analysis revealed that scores for urinary symptoms (urgency, frequency and nocturia), sleep disturbances (daytime sleep, restless legs), concentration, taste or smell were significantly associated with PD. Conclusions: Our data suggest that non-motor symptoms, particularly urinary symptoms, excessive daytime sleepiness, restless leg syndrome, attention deficit and hyposmia may be helpful to differentiate between DIP and PD in the early stages.
\end{abstract}

RÉSUMÉ: Symptômes non moteurs dans le parkinsonisme médicamenteux et dans la maladie de Parkinson jamais traitée. Contexte : Il est presque impossible de distinguer les manifestations cliniques du parkinsonisme médicamenteux (PM) et de la maladie de Parkinson (MP), ce qui rend difficile de distinguer le PM de la MP, surtout à un stade précoce de la maladie. Nous avons comparé au moyen de l'échelle NMS (Non Motor Symptoms Scale) les symptômes non moteurs (SNM) entre les patients présentant un PM et ceux atteints de la MP au début de la maladie et n'ayant jamais été traités. Méthode : Nous avons recruté de façon prospective 28 patients atteints de PM, 35 patients atteints de la MP jamais traités et 32 sujets témoins sans histoire de maladie neurologique ou de problèmes médicaux connexes. Nous avons examiné les caractéristiques démographiques, les antécédents médicaux et médicamenteux, les symptômes parkinsoniens moteurs et non moteurs de tous les sujets. Nous avons évalué les SNM au moyen de l'échelle NMS chez tous les sujets. Résultats : Les scores totaux à l'échelle NMS étaient plus élevés chez les patients atteints de la MP que chez ceux présentant un PM de même que les scores dans le domaine cardiovasculaire, le sommeil/la fatigue, le domaine urinaire et sexuel et divers autres domaines. Après ajustement pour l'âge et le sexe, l'analyse de corrélation a montré que les scores pour les symptômes urinaires (mictions impérieuses, pollakiurie et nycturie), les troubles du sommeil (le sommeil diurne, les jambes sans repos), la concentration, le goût ou l'odorat étaient associés de façon significative à la MP. Conclusions : Selon nos données, les SNM, particulièrement les symptômes urinaires, la somnolence diurne excessive, le syndrome des jambes sans repos, le déficit d'attention et les troubles de l'odorat peuvent aider à distinguer le PM de la MP au début de la maladie.

Can J Neurol Sci. 2013; 40: 36-41

Drug-induced parkinsonism (DIP) is the second most common cause of parkinsonism in older people after idiopathic Parkinson's disease (PD). ${ }^{1}$ This has been associated with the use of any drugs that either block dopamine receptors or deplete dopamine storage, including antipsychotic agents, ${ }^{2}$ antiemetics, ${ }^{3,4}$ and calcium channel antagonists. ${ }^{5}$ The clinical manifestations of DIP are indistinguishable from those of PD, including resting tremor and asymmetrical symptoms. ${ }^{6}$ Although most patients with DIP showed improvement within a few weeks after discontinuation of the offending drugs, ${ }^{7}$ some patients have persistent parkinsonian symptoms after discontinuation of the offending drug. It is not uncommon for physicians to misdiagnose DIP as PD, which may lead to the inappropriate use of dopaminergic medication and other potentially harmful adverse effects of drugs. Since the prognosis and treatment strategies for DIP and PD are different, it is important to distinguish between DIP and PD during the initial stages to ensure application of the appropriate therapeutic regimen. Although a few efforts using dopamine transporter (DAT) imaging to distinguish between DIP and $\mathrm{PD},{ }^{8}$ it is difficult to recommend these tools for all patients due to the economic burden and complexity of process.

Non-motor symptoms (NMSs) have received attention recently due to their precedence over cardinal motor symptoms

From the Department of Neurology (JSK, JY, HS, JWC), Samsung Medical Center, Sungkyunkwan University School of Medicine; Department of Neurology (JSK), Soonchunhyang University Hospital, Soonchunhyang University School of Medicine Seoul, Korea.

Received July 4, 2012. Final Revisions Submitted August 24, 2012. Correspondence to: Jin Whan Cho, Department of Neurology, Samsung Medical Center, Sungkyunkwan University School of Medicine, 50, Irwon-Dong, Gangnam-Gu Seoul, 135-710, Korea. Email: jinwhan.cho@samsung.com. 
in the early phases of PD. ${ }^{9}$ The recognition that specific NMSs, such as olfactory dysfunction, dysautonomia, mood and sleep disorders, occur in the premotor phase of PD has given rise to the possibility of early diagnosis of PD. Considering that DIP is caused by selective antagonism at striatal dopamine receptors, it may not be accompanied by the PD-specific NMSs that result from neurodegeneration of the brain stem nucleus. ${ }^{10}$ In the present study, we aimed to distinguish between DIP and drugnaïve $\mathrm{PD}$ in the early stages by NMSs using Non-Motor Symptoms Scale (NMSS) at initial stage in the patients with parkinsonism.

\section{Patients and Methods}

\section{Patients}

We prospectively enrolled 28 patients with DIP and 35 patients with drug-naïve PD in the early stages. Eligible patients met the following clinical criteria for DIP ${ }^{11}$ : (1)The presence of at least two of the four cardinal signs of PD (tremor, rigidity, bradykinesia, and impaired postural reflexes); (2) absence of a personal history of extrapyramidal disorders before treatment with an offending drug; and (3) onset of symptoms during the course of treatment with an offending drug. In addition, positron emission tomography (PET) using ${ }^{18} \mathrm{~F}-\mathrm{N}$-(3- fluoropropyl)2beta-carbonethoxy-3beta-(4-iodophenyl) nortropane (FP-CIT) was used to improve the diagnostic accuracy of DIP. We excluded patients suffering from severe medical diseases or psychosis. A clinical diagnosis of PD was made according to the UK Brain Bank criteria. ${ }^{12}$ To exclude the influence of levodopa on NMSs, we only included patients who were drug-naïve to anti-parkinsonian medications. All of the patients with PD and DIP underwent brain magnetic resonance imaging to exclude other possible causes of parkinsonism such as vascular lesion or tumors. We also enrolled 32 controls with no history of medical or neurological diseases and medications. This study was approved by Institutional Review Board of the Samsung Medical Center, Seoul, Korea and each patient provided informed consent to participate.

\section{Assessment}

We obtained demographic and historical information from all patients, including age, gender, causative drug (DIP patients only), underlying disease, detailed medical and drug histories, and time from symptom onset to diagnosis of parkinsonism. In addition, a complete neurological examination, including the motor portion of the Unified Parkinson's Disease Rating Scale (UPDRS Part III) and Hoehn and Yahr (H\&Y) stage, was performed. To measure NMSs, we used NMSS, ${ }^{13}$ a widely-used scale of NMSs identification consisting of cardiovascular, sleep/fatigue, mood/cognition, perceptual problems, attention/ memory, gastrointestinal, urinary, sexual function, and miscellaneous domains.

\section{Statistical analysis}

The statistical analysis was performed with SPSS version 18.0 (Chicago, IL, USA). Kruskal-Wallis tests with Bonferroni post hoc testing were used to compare NMSS scores between the DIP, PD, and control groups. To determine the correlation between each measurement and the diagnosis of DIP or PD while controlling for age and gender, partial Spearman correlation analyses were used. The significance threshold was set to 0.05 . Nonparametric tests and one-way analysis of variance (ANOVA) were used to compare demographic variables.

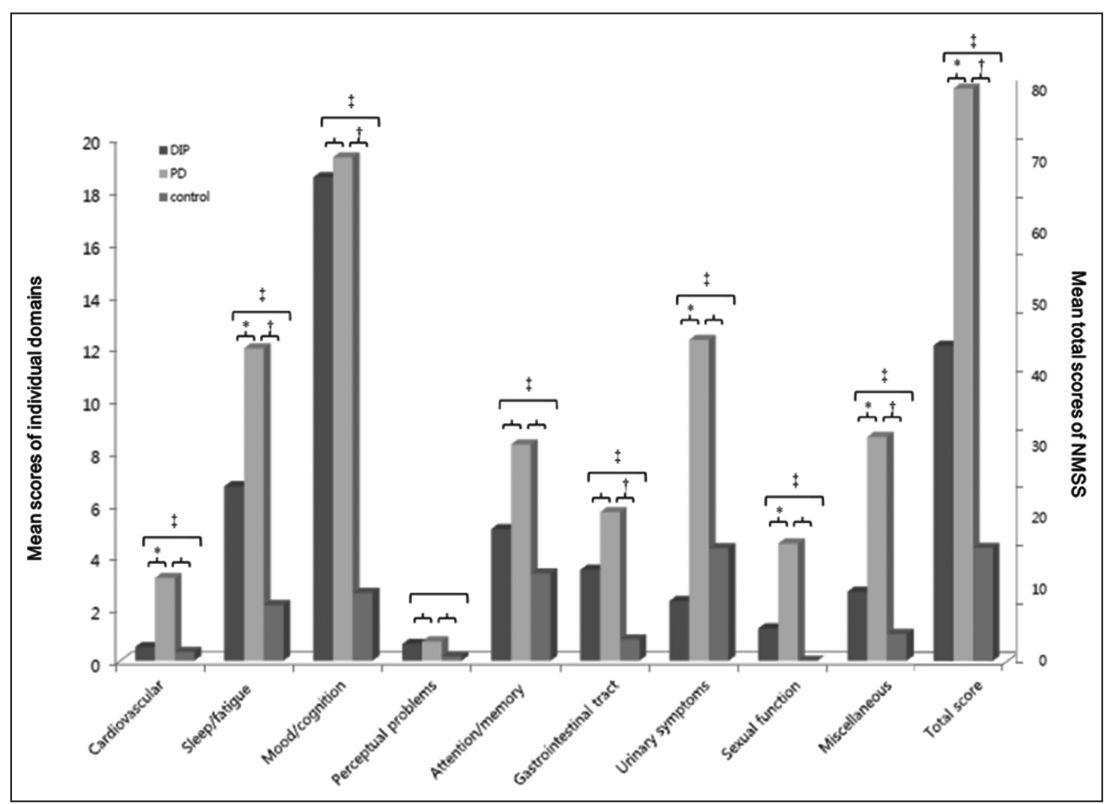

Figure: Comparison of nine NMSS domains and total score among DIP, PD and control group. Analyses were performed by Kruskal Wallis test, with Bonferroni post hoc paired comparison tests. ${ }^{*} p$ indicate significant correlations between DIP and PD group. $\dagger p$ indicate significant correlations between $P D$ and control group. $\$ p$ indicate significant correlations between DIP and control group. NMSS, Non-motor symptoms scale; DIP, drug induced parkinsonism; $P D$, Parkinson's disease. 
Table 1: Demographic characteristics in patients with DIP

\begin{tabular}{|c|c|c|c|c|c|c|c|c|c|c|}
\hline No. & Age & Sex & Drug & Dur.(mo.) & $\begin{array}{l}\text { Initial UPDRS } \\
\text { (part III) }\end{array}$ & $\begin{array}{l}\mathrm{H} \& \mathrm{Y} \\
\text { stage }\end{array}$ & $\begin{array}{l}\text { F/U UPDRS } \\
\text { (part III) }\end{array}$ & Sym & Add feature & PET \\
\hline 1 & 75 & $\mathrm{M}$ & Levosulpiride & 4 & 26 & 2 & 16 & sym & None & Normal \\
\hline 2 & 67 & $\mathrm{M}$ & Haloperidol & 2 & 45 & 2 & 40 & sym & Tongue dyskinesia & Normal \\
\hline 3 & 83 & F & Levosulpiride & 5 & 40 & 2.5 & NA & sym & OMD & Normal \\
\hline 4 & 65 & $\mathrm{~F}$ & Flunarizine & 12 & 28 & 2.5 & 5 & asym & None & Normal \\
\hline 5 & 62 & M & Flunarizine & 1 & 16 & 2 & 5 & asym & None & Normal \\
\hline 6 & 72 & F & Levosulpiride & 1 & 24 & 2.5 & 20 & sym & None & Normal \\
\hline 7 & 84 & $\mathrm{~F}$ & Flunarizine & 3 & 16 & 2 & 10 & asym & None & Normal \\
\hline 8 & 73 & $\mathrm{~F}$ & Levosulpiride & 15 & 27 & 2 & 20 & asym & None & Normal \\
\hline 9 & 70 & $\mathrm{~F}$ & Flunarizine & 48 & 14 & 1 & 4 & sym & None & NA \\
\hline 10 & 78 & $\mathrm{~F}$ & Levosulpiride & 48 & 22 & 2 & 9 & sym & None & NA \\
\hline 11 & 58 & $\mathrm{~F}$ & Flunarizine & 1 & 42 & 3 & 2 & sym & OMD & Normal \\
\hline 12 & 63 & $\mathrm{~F}$ & Levosulpiride & 4 & 10 & 2 & 2 & sym & None & NA \\
\hline 13 & 84 & $\mathrm{~F}$ & Levosulpiride & 1 & 5 & 1 & 1 & sym & OMD & NA \\
\hline 14 & 61 & $\mathrm{~F}$ & Risperidone & 7 & 16 & 2 & 10 & sym & OMD & NA \\
\hline 15 & 68 & $\mathrm{~F}$ & Levosulpiride & 1 & 18 & 2 & 10 & sym & None & NA \\
\hline 16 & 58 & $\mathrm{~F}$ & Chloropromazine & 6 & 35 & 3 & NA & sym & None & Normal \\
\hline 17 & 76 & $\mathrm{~F}$ & Amisulpiride & 5 & 9 & 1 & 3 & sym & None & NA \\
\hline 18 & 70 & $\mathrm{~F}$ & Levosulpiride & 6 & 11 & 2 & 0 & asym & None & Normal \\
\hline 19 & 66 & $\mathrm{~F}$ & Flunarizine & 3 & 23 & 2 & 3 & sym & None & Normal \\
\hline 20 & 88 & F & Levosulpiride & 8 & 10 & 1.5 & 6 & sym & OMD & NA \\
\hline 21 & 67 & M & Levosulpiride & 3 & 3 & 1 & 2 & sym & None & Normal \\
\hline 22 & 73 & M & Metoclopramide & 4 & 29 & 2.5 & 12 & sym & Tongue dyskinesia & Normal \\
\hline 23 & 72 & $\mathrm{~F}$ & Levosulpiride & 4 & 13 & 2 & 6 & sym & Facial tremor & Normal \\
\hline 24 & 69 & $\mathrm{~F}$ & Levosulpiride & 2 & 29 & 2.5 & 2 & sym & None & Normal \\
\hline 25 & 61 & $\mathrm{~F}$ & Levosulpiride & 19 & 26 & 3 & 16 & asym & None & Normal \\
\hline
\end{tabular}

Drug, offending drug; Dur. (mo.), Symptom duration (month); H \& Y stage, Hoehn and Yahr stage; F/U, follow up; Sym, symmetry; Add feature, Additional feature; M, male; F, female; sym, symmetric; asym, asymmetric; HTN, Hypertension; OMD, oromandibular dyskinesia; HA, Headache; TIA, Transient ischemic attack; ET, Essential tremor; LBP, Low back pain; Schizo, Schizophrenia; DM, diabetes mellitus; NA, not available.

\section{RESULTS}

\section{Patient characteristics}

Among patients with DIP, levosulpiride (57\%) was the most common offending drug, followed by flunarizine (21.4\%) (Table 1). Most patients with DIP showed relatively subacute onset after exposure of offending drug and symmetric motor features and seven patients showed additional features such as oromandibular dyskinesia. Twenty of 28 patients (71.4\%) with DIP were evaluated with FP-CIT PET. Three of these patients had reduced FP-CIT binding in the posterior putamen, and they were excluded from further analysis because they were considered as DIP with subclinical PD. Eight patients who did not undergo FPCIT PET demonstrated an improvement in parkinsonian symptoms, although not necessarily completely, after discontinuing use of the offending drugs during follow-up for more than three months without anti-parkinsonian medication. Table 2 depicts the characteristics of the DIP, PD, and control

Table 2: Demographic characteristics in DIP, PD and control group, $n, n(\%)$, mean \pm S.D

\begin{tabular}{llllll}
\hline & DIP & PD & Control & $P$ & Post-hoc comparison \\
\hline No. of subject & 25 & 35 & 32 & & \\
No. of females & $20(80 \%)$ & $15(42.9 \%)$ & $16(50 \%)$ & $0.011^{*}$ & \\
Age(years) & $70.52 \pm 8.307$ & $61.09 \pm 10.133$ & $68.39 \pm 9.994$ & $<0.001 \dagger$ & DIP=control $>$ PD \\
Symptom duration(months) & $8.52 \pm 12.686$ & $15.71 \pm 15.221$ & & $0.008^{*}$ & \\
UPDRS part III & $21.080 \pm 11.391$ & $16.286 \pm 9.958$ & & 0.053 & \\
H \& Y stage & $2.040 \pm 0.593$ & $1.543 \pm 0.586$ & & $0.003^{*}$ & \\
\hline
\end{tabular}

Analyses were performed by one-way analysis of variance (ANOVA), with Bonferroni post hoc paired comparison tests for age. ${ }^{*} \mathrm{p}(<0.05)$ indicate significant correlations. $\dagger \mathrm{p}(<0.001)$ indicate significant correlations. DIP, drug induced parkinsonism; PD, Parkinson's disease. 
Table 3: Comparison of scores for individual items in NMSS among DIP, PD and control group

\begin{tabular}{|c|c|c|c|c|c|c|c|c|c|c|c|c|}
\hline & DIP & & & $\mathrm{PD}$ & & & Contro & & & $\mathrm{F}$ & $P$ value & Post-hoc comp. \\
\hline & Mean & Med. & Max. & Mean & Med. & Max. & Mean & Med. & Max. & & & \\
\hline \multicolumn{13}{|l|}{ Cardiovascular } \\
\hline Light-headedness & 0.36 & 0 & 4 & 2.09 & 0 & 12 & 0.34 & 0 & 4 & 5.000 & $0.009 *$ & $\mathrm{PD}>$ control \\
\hline Fainting & 0.16 & 0 & 2 & 1.09 & 0 & 12 & 0 & 0 & 0 & 3.700 & $0.029^{*}$ & $\mathrm{PD}>$ control \\
\hline \multicolumn{13}{|l|}{ Sleep/fatigue } \\
\hline Daytime sleep & 0.40 & 0 & 8 & 1.69 & 0 & 12 & 0.28 & 0 & 4 & 8.595 & $<0.001 \dagger$ & $\mathrm{PD}>\mathrm{DIP}=$ control \\
\hline Fatigue & 2.20 & 1 & 12 & 3.14 & 2 & 12 & 0.72 & 0 & 6 & 9.740 & $<0.001 \dagger$ & $\mathrm{PD}=\mathrm{DIP}>$ control \\
\hline Difficulty fall asleep & 3.56 & 1 & 12 & 4.17 & 3 & 12 & 0.44 & 0 & 4 & 10.409 & $<0.001 \dagger$ & $\mathrm{PD}=\mathrm{DIP}>$ control \\
\hline Restless legs & 1.00 & 0 & 2 & 2.97 & 0 & 12 & 0.69 & 0 & 6 & 5.041 & $0.008^{*}$ & $\mathrm{PD}>\mathrm{DIP}=$ control \\
\hline \multicolumn{13}{|l|}{ Mood/cognition } \\
\hline Lost interest. & 3.16 & 1 & 12 & 2.60 & 1 & 12 & 0.34 & 0 & 4 & 8.635 & $<0.001 \dagger$ & $\mathrm{PD}=\mathrm{DIP}>$ control \\
\hline Lack motivation & 3.40 & 2 & 12 & 3.11 & 1 & 12 & 0.22 & 0 & 4 & 12.527 & $<0.001 \dagger$ & $\mathrm{PD}=\mathrm{DIP}>$ control \\
\hline Feel nervous & 2.40 & 0 & 12 & 3.86 & 2 & 12 & 0.34 & 0 & 4 & 12.132 & $<0.001 \dagger$ & $\mathrm{PD}=\mathrm{DIP}>$ control \\
\hline Seem sad & 3.04 & 1 & 12 & 2.89 & 0 & 12 & 0.81 & 0 & 12 & 6.868 & $0.002 *$ & $\mathrm{PD}=\mathrm{DIP}>$ control \\
\hline Flat mood & 2.80 & 0 & 12 & 2.97 & 4 & 8 & 0.50 & 0 & 8 & 14.793 & $<0.001 \dagger$ & $\mathrm{PD}=\mathrm{DIP}>$ control \\
\hline Difficult feel pleasure & 3.72 & 1 & 12 & 3.83 & 3 & 12 & 0.50 & 0 & 8 & 12.559 & $<0.001 \uparrow$ & $\mathrm{PD}=\mathrm{DIP}>$ control \\
\hline \multicolumn{13}{|l|}{ Perceptual problems } \\
\hline Hallucinations & 0.04 & 0 & 1 & 0.23 & 0 & 4 & 0 & 0 & 0 & 2.272 & 0.109 & $\mathrm{PD}=\mathrm{DIP}=$ control \\
\hline Delusions & 0.40 & 0 & 9 & 0.29 & 0 & 4 & 0 & 0 & 0 & 1.845 & 0.164 & $\mathrm{PD}=\mathrm{DIP}=$ control \\
\hline Double vision & 0.20 & 0 & 4 & 0.23 & 0 & 4 & 0.03 & 0 & 1 & 0.839 & 0.436 & $\mathrm{PD}=\mathrm{DIP}=$ control \\
\hline \multicolumn{13}{|l|}{ Attention/memory } \\
\hline Concentration & 1.36 & 0 & 12 & 3.89 & 1 & 12 & 1.13 & 0 & 8 & 4.983 & $0.009^{*}$ & $\mathrm{PD}>\mathrm{DIP}=$ control \\
\hline Forget things or events & 2.36 & 0 & 12 & 2.71 & 1 & 12 & 1.25 & 0 & 12 & 1.223 & 0.299 & $\mathrm{PD}=\mathrm{DIP}=$ control \\
\hline Forget to do things & 1.32 & 0 & 12 & 1.69 & 0 & 12 & 0.97 & 0 & 8 & 0.988 & 0.376 & $\mathrm{PD}=\mathrm{DIP}=$ control \\
\hline \multicolumn{13}{|l|}{ Gastrointestinal tract } \\
\hline Saliva & 0.44 & 0 & 4 & 1.17 & 0 & 12 & 0.03 & 0 & 1 & 4.657 & $0.012 *$ & $\mathrm{PD}>$ control \\
\hline Swallowing & 0.48 & 0 & 6 & 1.43 & 0 & 12 & 0.56 & 0 & 12 & 1.633 & 0.201 & $\mathrm{PD}=\mathrm{DIP}=$ control \\
\hline Constipation & 1.76 & 0 & 9 & 3.09 & 1 & 12 & 0.22 & 0 & 6 & 11.325 & $<0.001 \uparrow$ & $\mathrm{PD}=\mathrm{DIP}>$ control \\
\hline \multicolumn{13}{|l|}{ Urinary symptoms } \\
\hline Urgency & 0.68 & 0 & 12 & 3.46 & 1 & 12 & 1.31 & 0 & 12 & 6.018 & $0.004 *$ & $\mathrm{PD}>\mathrm{DIP}=$ control \\
\hline Frequency & 0.40 & 0 & 4 & 4.00 & 2 & 12 & 1.13 & 0 & 12 & 10.684 & $<0.001 \dagger$ & $\mathrm{PD}>\mathrm{DIP}=$ control \\
\hline Nocturia & 1.68 & 0 & 12 & 4.83 & 3 & 12 & 1.88 & 0 & 12 & 5.851 & $0.004 *$ & $\mathrm{PD}>\mathrm{DIP}=$ control \\
\hline \multicolumn{13}{|l|}{ Sexual function } \\
\hline Interest in sex & 0.64 & 0 & 8 & 2.37 & 0 & 12 & 0 & 0 & 8 & 10.525 & $<0.001 \dagger$ & $\mathrm{PD}>\mathrm{DIP}=$ control \\
\hline Problems having sex & 0.60 & 0 & 8 & 2.11 & 0 & 12 & 0 & 0 & 0 & 8.584 & $<0.001 \dagger$ & $\mathrm{PD}>\mathrm{DIP}=$ control \\
\hline \multicolumn{13}{|l|}{ Miscellaneous } \\
\hline Pains & 0.64 & 0 & 6 & 2.66 & 0 & 12 & 0.13 & 0 & 4 & 9.376 & $<0.001 \dagger$ & $\mathrm{PD}>\mathrm{DIP}=$ control \\
\hline Taste or smell & 0.56 & 0 & 4 & 3.80 & 1 & 12 & 0.38 & 0 & 8 & 13.899 & $<0.001 \dagger$ & $\mathrm{PD}>\mathrm{DIP}=$ control \\
\hline Weight change & 0.44 & 0 & 2 & 0.97 & 0 & 12 & 0 & 0 & 0 & 8.476 & $<0.001 \dagger$ & $\mathrm{PD}=\mathrm{DIP}>$ control \\
\hline Excessive sweating & 1.00 & 0 & 12 & 1.09 & 0 & 12 & 0.53 & 0 & 12 & 2.166 & 0.121 & $\mathrm{PD}=\mathrm{DIP}=$ control \\
\hline
\end{tabular}

$* \mathrm{p}(<0.05)$ indicate significant correlations. $\dagger \mathrm{p}(<0.001)$ indicate significant correlations. NMSS, Non-motor symptoms scale; DIP, drug induced parkinsonism; PD, Parkinson's disease; Med, median; Max, Maxium; post-hoc comp, post-hoc comparison.

groups. The patients in the DIP group were older and had a higher female-to-male ratio than patients in the PD group. The duration of parkinsonism from symptom onset to time to diagnosis was significantly shorter in the DIP group than the PD group. The motor function (UPDRS part III, H \& Y stage) was worse in DIP patients than PD patients; however, the difference of UPDRS part III was not significant.

\section{Comparisons of each domain and item of the NMSS}

Total NMSS score was significantly higher in the PD group than the DIP group. When each of the nine NMSS domains were compared among the three groups in post hoc analyses, the scores for the cardiovascular, sleep/fatigue, urinary, sexual function, and miscellaneous domains were higher in the PD group than the DIP group. (Figure) Most of the individual items of the NMSS were significantly different among the three groups (Table 3). The post hoc analyses showed that the scores for sleep disturbance including daytime sleep, restless legs; concentration; urinary symptoms including urgency, frequency, and nocturia; sexual dysfunction including interest in sex and problems having sex; miscellaneous symptoms including pain, taste and smell were significantly higher in the PD group than the DIP group.

\section{Correlation analysis}

Table 4 depicts the results of the correlation analysis that controlled for age and gender. The correlation of measures related to motor function (higher UPDRS part III and $\mathrm{H} \& \mathrm{Y}$ stage) with DIP was low to moderate $\left(r_{s}=0.270-0.417\right)$. For each individual item of the NMSS, urgency, frequency, nocturia, daytime sleep, concentration, taste or smell were moderately associated with PD $\left(r_{s}=0.328-0.481\right)$. Only a weak association was found between restless legs and PD $\left(r_{s}=0.264\right)$. Significant correlations were not found for the remaining items.

\section{Discussion}

To our knowledge, this is the first study to compare NMSs between patients with DIP and PD using the NMSS. To rule out the possibility of a medication effect, ${ }^{14}$ we only included antiparkinsonian drug-naïve patients. We found that the total NMSS scores were significantly greater in patients with PD than with DIP, and the scores for certain symptoms, such as urinary symptoms, including frequency, urgency, and nocturia; sleep disturbances, including excessive daytime sleepiness (EDS) and restless leg syndrome (RLS); attention deficit; and hyposmia were significantly correlated with PD, suggesting that NMSs, especially the specific ones listed above, might be useful for 
differentiating between patients with PD and those with DIP in the early stages.

Most antipsychotic agents work by inhibiting transmission in the mesocorticolimbic system, and they simultaneously cause extrapyramidal symptoms by inhibiting transmission in the nigrostriatal system. ${ }^{15}$ Levosulpiride $^{3}$ and the newer calciumchannel blockers, such as flunarizine and cinnarizine, ${ }^{5}$ also cause parkinsonism by inhibiting the dopamine D2 receptor. These drugs produce a functional dopaminergic-deficient state and hence cause clinical symptoms that mimic PD. According to Braak et al, ${ }^{10}$ PD may be initiated by the deposition of Lewy bodies in involved nerve cells in the caudal brainstem, and this pathological process has an ascending temporal sequence that develops to affect other parts of the brain, causing various NMSs. Before the emergence of the traditional motor triad of tremor, rigidity, and bradykinesia caused by neurodegeneration in the substantia nigra and other deep nuclei of the midbrain and forebrain - so-called "premotor phase", olfactory dysfunction, dysautonomia, sleep and mood disturbances might be preceded by affecting olfactory bulb or brainstem nuclei such as raphe nucleus, locus coeruleus, pedunculopontine nucleus and dorsal motor nucleus of vagus. ${ }^{9,16}$ Considering that DIP occurs through selective antagonism of the dopaminergic pathway, NMSs specific to PD that are caused by a degenerative process in the brain stem may be uncommon in DIP.

To date, possible pre-motor symptoms for PD of which there is strong or suggestive evidence include olfactory deficit; constipation; sleep disorders, such as EDS and rapid eye movement sleep behavior disorder (RBD); and depression. ${ }^{9,16-18}$ Recent studies that investigated the whole spectrum of NMSs in PD also showed a high frequency of certain NMSs in patients with PD, even in the early stages..$^{19,20}$ We found a significant correlation between PD and urinary frequency, urgency, and nocturia; EDS and RLS; attention deficit; and hyposmia, results that are generally consistent with those of previous studies. Since the brain stem structures responsible for the above symptoms of PD are already involved in Braak stages $2-3,{ }^{10}$ these problems may be part of the prodromal phase and could be helpful to recognize $\mathrm{PD}$ in the early stage compared with DIP. Gastrointestinal problems, one of the possible NMSs with strong evidence, were not significantly different between patients with PD and DIP in this study. Considering that the most common causative drug for DIP was levosulpiride, most patients with DIP may have had underlying gastrointestinal problems.

The cardiovascular, perceptual, sexual, mood/cognition, and attention/memory domains (with the exception of concentration) failed to show significant correlations with PD in this study. Although the prevalence of these symptoms is high in patients with $\mathrm{PD},{ }^{21-25}$ these diagnoses are also common in the general population, so they have low sensitivity and specificity in predicting subsequent Parkinson's disease. ${ }^{26}$ Since we only included drug-naïve patients in the early stages of PD, this may explain why the frequencies of complaints related to the cardiovascular system and perceptual problems were generally low; these symptoms are uncommon in early $\mathrm{PD}^{9}$ but become more frequent as the disease progresses. ${ }^{27}$ The patients with DIP demonstrated poorer motor function and had a shorter disease duration than those with PD, so the relatively subacute onset and more severe parkinsonism of the DIP patients might have influenced the results on mood. Furthermore, four patients had
Table 4: Correlation analysis between diagnosis of DIP or PD and measures related parkinsonism, each item of NMSS after controlling for age and gender

\begin{tabular}{|c|c|c|}
\hline & Spearman $r_{s}$ & $P$ \\
\hline Duration & 0.139 & 0.303 \\
\hline UPDRS motor score & -0.270 & $0.042 *$ \\
\hline H \& Y stage & -0.417 & $0.001 *$ \\
\hline \multicolumn{3}{|l|}{ Cardiovascular } \\
\hline Light-headedness & 0.248 & 0.063 \\
\hline Fainting & 0.062 & 0.647 \\
\hline \multicolumn{3}{|l|}{ Sleep/fatigue } \\
\hline Daytime sleep & 0.391 & $0.003 *$ \\
\hline Fatigue & 0.194 & 0.148 \\
\hline Difficulty falling asleep & 0.096 & 0.477 \\
\hline Restless legs & 0.264 & $0.047 *$ \\
\hline \multicolumn{3}{|l|}{ Mood/cognition } \\
\hline Lost interest in surroundings & -0.059 & 0.665 \\
\hline Lack motivation & 0.002 & 0.988 \\
\hline Feel nervous & 0.255 & 0.055 \\
\hline Seem sad & 0.093 & 0.492 \\
\hline Flat mood & 0.067 & 0.618 \\
\hline Difficulty experiencing pleasure & 0.021 & 0.878 \\
\hline \multicolumn{3}{|l|}{ Perceptual problems } \\
\hline Hallucinations & 0.191 & 0.156 \\
\hline Delusions & 0.093 & 0.493 \\
\hline Double vision & 0.068 & 0.617 \\
\hline \multicolumn{3}{|l|}{ Attention/memory } \\
\hline Concentration & 0.390 & $0.003 *$ \\
\hline Forget things or events & 0.152 & 0.259 \\
\hline Forget to do things & 0.161 & 0.232 \\
\hline \multicolumn{3}{|l|}{ Gastrointestinal tract } \\
\hline Saliva & -0.002 & 0.990 \\
\hline Swallowing & 0.254 & 0.057 \\
\hline Constipation & 0.196 & 0.143 \\
\hline \multicolumn{3}{|l|}{ Urinary symptoms } \\
\hline Urgency & 0.346 & $0.008 *$ \\
\hline Frequency & 0.481 & $<0.001 \dagger$ \\
\hline Nocturia & 0.328 & $0.013 *$ \\
\hline \multicolumn{3}{|l|}{ Sexual function } \\
\hline Interest in sex & 0.174 & 0.196 \\
\hline Problems having sex & 0.153 & 0.256 \\
\hline \multicolumn{3}{|l|}{ Miscellaneous } \\
\hline Pains & 0.182 & 0.176 \\
\hline Taste or smell & 0.438 & $0.001 *$ \\
\hline Weight change & 0.175 & 0.193 \\
\hline Excessive sweating & -0.055 & 0.684 \\
\hline
\end{tabular}

rs $=$ partial correlation coefficient adjusted by age and gender. $* \mathrm{p}$ $(<0.05)$ indicate significant correlations. $\dagger \mathrm{p}(<0.001)$ indicate significant correlations. NMSS, nonmotor symptoms scale; DIP, drug induced parkinsonism; PD, Parkinson's disease; UPDRS, Unified Parkinson's Disease Rating Scale; H \& Y, Hoehn and Yahr. 
taken neuroleptics for psychiatric illness including anxiety, depression, schizophrenia and bipolar disorder. These drugs might influence on behavior and mood status, mood domain might not show difference between patients with PD and DIP.

Our study has several limitations. First, the NMSS does not assess RBD, which is a well-known premotor symptom with strong pathological support. Hence, we could not investigate all possible premotor symptoms in this study. Second, we evaluated a relatively small sample of patients at a single medical facility, so our findings may not be representative of all patients with DIP. Third, we could not exclude the possibility that patients with subclinical PD were included in the DIP group. However, twenty of 28 patients with DIP had their diagnosis confirmed by FP-CIP PET scan, and clinical phenotype of patients with DIP showed subacute onset and symmetric motor symptoms, and combined with oromandibular dyskinesia. Furthermore, we observed an improvement in parkinsonism after discontinuing the offending drugs during follow-up of more than three months and excluded the patient who showed reduced FP-CIT binding in the posterior putamen from analysis. Fourth, demographics such as age and gender are significantly different between the DIP and PD group and this might affect the results. However, there were previous reports that showed no significant differences in NMSs by gender. ${ }^{20}$ Furthermore, we analyzed data with adjustment of different demographic factors including age and gender.

The present study is the first to use NMSs to distinguish between DIP and PD. The NMSS is simpler to administer and less invasive and expensive than DAT imaging. We suggest that NMSs, particularly urinary symptoms, hyposmia, EDS, RLS, and attention deficit, may help physicians distinguish between patients with DIP and patients with PD in the early stages. A careful assessment of NMSs may not only assist differentiation between DIP and PD, but also help ensure that patients with parkinsonism receive appropriate and timely treatment.

\section{REFERENCES}

1. Barbosa MT, Caramelli P, Maia DP, et al. Parkinsonism and Parkinson's disease in the elderly: A community-based survey in Brazil (the Bambuí study). Mov Disord. 2006;21:800-8.

2. Janno S, Holi M, Tuisku K, et al. Prevalence of neuroleptic-induced movement disorders in chronic schizophrenia inpatients. Am J psychiatry. 2004;161:160-3.

3. Shin H-W, Kim MJ, Kim JS, et al. Levosulpiride-induced movement disorders. Mov Disord. 2009;24:2249-53.

4. Ganzini L, Casey DE, Hoffman WF, et al. The prevalence of metoclopramide-induced tardive dyskinesia and acute extrapyramidal movement disorders. Arch Intern Med. 1993; 153:1469-75.

5. Brucke T, Wober C, Podreka I, et al. D2 receptor blockade by flunarizine and cinnarizine explains extrapyramidal side effects. A SPECT study. J Cereb Blood Flow Metab. 1995;15:513-8.

6. Hardie RJ, Lees AJ. Neuroleptic-induced Parkinson's syndrome: clinical features and results of treatment with levodopa. J Neurol Neurosurg Psychiatry. 1988;51:850-4.

7. Burn DJ, Brooks DJ. Nigral dysfunction in drug-induced parkinsonism: An 18F-dopa PET study. Neurology. 1993;43: 552-6.

8. Lorberboym M, Treves TA, Melamed E, et al. [123I]-FP/CIT SPECT imaging for distinguishing drug-induced parkinsonism from Parkinson's disease. Mov Disord. 2006;21:510-4.

9. Tolosa E, Gaig C, Santamaria J, et al. Diagnosis and the premotor phase of Parkinson disease. Neurology. 2009;72:S12-20.
10. Braak H, Del Tredici K, Rüb U, et al. Staging of brain pathology related to sporadic Parkinson's disease. Neurobiol Aging. 2003; 24:197-211.

11. Lee PH, Kim JS, Shin DH, et al. Cardiac 123I-MIBG scintigraphy in patients with drug induced parkinsonism. J Neurol Neurosurg Psychiatry. 2005;77:372-4.

12. Hughes AJ, Daniel SE, Kilford L, et al. Accuracy of clinical diagnosis of idiopathic Parkinson's disease: a clinicopathological study of 100 cases. J Neurol Neurosurg Psychiatry. 1992;55:181-4

13. Chaudhuri KR, Martinez-Martin P, Brown RG, et al. The metric properties of a novel non-motor symptoms scale for Parkinson's disease: Results from an international pilot study. Mov Disord. 2007;22:1901-11.

14. Park A, Stacy M. Dopamine-induced nonmotor symptoms of Parkinson's disease. Parkinsons Dis. 2011;2011:1-6.

15. Thanvi B, Treadwell S. Drug induced parkinsonism: a common cause of parkinsonism in older people. Postgrad Med. 2009;85: 322-6.

16. Chaudhuri KR, Healy DG, Schapira AH. Non-motor symptoms of Parkinson's disease: diagnosis and management. Lancet Neurol. 2006;5:235-45.

17. Lang AE. A critical appraisal of the premotor symptoms of Parkinson's disease: Potential usefulness in early diagnosis and design of neuroprotective trials. Mov Disord. 2011;26:775-83.

18. Wolters EC. Non-motor extranigral signs and symptoms in Parkinson's disease. Parkinsonism Relat Disord. 2009;15S3: S6-12.

19. Barone P, Antonini A, Colosimo C, et al. The PRIAMO study: A multicenter assessment of nonmotor symptoms and their impact on quality of life in Parkinson's disease. Mov Disord. 2009;24: 1641-9.

20. Martinez-Martin P, Schapira AH, Stocchi F, et al. Prevalence of nonmotor symptoms in Parkinson's disease in an international setting; Study using nonmotor symptoms questionnaire in 545 patients. Mov Disord. 2007;22:1623-9.

21. Reijnders JS, Ehrt U, Weber WE, et al. A systematic review of prevalence studies of depression in Parkinson's disease. Mov Disord. 2008;23:183-9.

22. Bosboom JL, Stoffers D, Wolters ECh. Cognitive dysfunction and dementia in Parkinson's disease. J Neural Transm. 2004;111: 1303-15.

23. Elgh E, Domellof M, Linder J, et al. Cognitive function in early Parkinson's disease: a population-based study. Eur J Neurol. 2009;16:1278-84.

24. Braak H, Rüb U, Jansen Steur EN, et al. Cognitive status correlates with neuropathologic stage in Parkinson disease. Neurology. 2005;64:1404-10

25. Bohnen NI, Kaufer DI, Ivanco LS, et al. Cortical cholinergic function is more severely affected in parkinsonian dementia than in Alzheimer disease: an in vivo positron emission tomographic study. Arch Neurol. 2003;60:1745-8.

26. Shiba M, Bower JH, Maraganore DM, et al. Anxiety disorders and depressive disorders preceding Parkinson's disease: a casecontrol study. Mov Disord. 2000;15:669-77.

27. Diederich NJ, Goetz CG, Stebbins GT. Repeated visual hallucinations in Parkinson's disease as disturbed external/internal perceptions: Focused review and a new integrative model. Mov Disord. 2005;20:130-40. 